\title{
Editorial: Informatics for sustainable energy development and environmental management
}

\author{
Yanpeng Cai
}

Energy demand and supply are of fundamental importance to the society due to their impacts on various environmental and economic activities (Schweizer-Ries, 2008; Jin et al., 2010). Although energy-related and environmental concerns are originally local (e.g., environmental problems associated with extraction, transport, conversion and consumption of energy resources), they have recently been extended to issues at multiple spatial scales, such as global effects of large-scale energy activities, international energy trade and pollutant-emission conflicts, and regional energy allocation and environmental management (Huang and Chang, 2003; Yuksel, 2012). Moreover, these issues are being further complicated by rising energy prices, shrinking energy reserves, and varying legislational, geographic, socio-economic and political conditions, leading to a variety of complexities in the relevant decision-making processes (Matsuhashi et al., 1996; Verderame et al., 2010). In order to systematically analyze environmental effects of energy activities and optimally allocate energy resources/services for supporting sustainable energy development, it is desired that effective policy analysis and decision-support techniques be developed (Huang and Chang, 2003; Olabi, 2012).

The purpose of this special issue is thus to report some of the latest research related to the evolving area, which addresses various issues of sustainable energy development and environmental management. The Guest Editors of this special issue of Environmental Systems Research an International Journal have therefore invited experts, to share their knowledge by reviewing and studying most of the key aspects of "Informatics for Sustainable Energy Development and Environmental Management". Given the multidisciplinary and collaborative nature of inquiries into the interaction between energy and environment, the contributions incorporate diversified and creative applications of theories and methodologies from various fields including decision support systems (DSS), economics,

Correspondence: yanpeng.cai@iseis.org

Institute for Energy, Environment and Sustainable Communities - Environment Canada, University of Regina, Regina, Saskatchewan S4S 7H9, Canada management, optimization and simulation, and information science.

Papers appearing in this special issue are selected from over 60 papers. Following a peer-review process, four papers were finally selected for publication, covering a variety of cutting-edge research topics. It is expected that publication of these research works will help initiate extensive discussions in terms of methodologies and case studies of "Informatics for Sustainable Energy Development and Environmental Management".

Davison et al. analyzed state variables of natural environment (such as temperature, wind speed, and ice cover) that were highly related to energy extraction, production, and transmission systems. Predictions of such variables could provide useful information to energy managers and decision makers. Three selected Canadian case studies were carried out to demonstrate how useful the prediction information could be used for supporting energy and environmental management. Considering economic issues of prediction, economically valuable forecasts and economically less valuable forecasts were examined. It was found in this paper that the risk aversion of decision makers, the degree to which the decision had multiple inputs, and the certainty of the forecasts, together with the sensitivity of the system to the environmental state variable in question, all played important roles. To the extent that risk aversion results from government regulations and organizational guidelines, the conclusions in this paper suggested that possible changes in public policy and industrial practices could help manage energy resources through the forecast of environmental state variables.

Yeomans investigated a number of school districts in Toronto. It was found that the Toronto District School Board (TDSB) oversaw the largest school district in Canada and spent more than one third of its annual maintenance budget on energy consumption and waste disposal. This had directed attention toward system-wide reductions to both energy consumption patterns and waste generation rates. In order to deal with such an issue, a decision support system (DSS) was presented in this paper. It could 
effectively process unit-incompatible measures that were used for rating, ranking, and benchmarking the schools within TDSB. The developed DSS determined realistic improvement targets and could also explicitly rank each school within the district. The results indicated that achieving these benchmarks would reduce system-wide energy costs by twenty-five percent.

In the study of Qin et al., a fuzzy confidence model coupled with mixed-integer programming was proposed for regional energy systems planning. Application of the model to a hypothetical case indicated that the model was capable of handling uncertainties expressed as fuzzy sets and taking capacity-expansion issues of energy facilities into consideration. The solutions from the proposed model could meet system constraints at different confidence levels, where each confidence level was further associated with different reliability scenarios. The proposed model could help decision makers analyze the trade-offs between system economy and reliability, and explore cost-effective energy systems planning strategies under uncertainty.

In the work of Wang et al., an interval mixed-integer non-linear programming (IMINLP) model was developed to assist regional electric power systems planning under uncertainty. $\mathrm{CO}_{2}$ capture and storage (CCS) technologies had been introduced to the IMINLP model to help reduce carbon emission. The developed IMINLP model could be disassembled into a number of ILP models, then a two-step method (TSM) was used to obtain the optimal solutions. A case study was provided for demonstrating applicability of the developed method. The results indicated that the developed model was capable of providing alternative decisions based on scenario analysis for electricity planning with consideration of CCS technologies. The IMINLP model could provide an effective linkage between carbon sequestration and electric generating capacity expansion with the aim of minimizing system costs.

In general, these four papers are concerned with various aspects of "Informatics for Sustainable Energy Development and Environmental Management", where a number of new perspectives and findings are proposed. They are founded on various methodologies in the fields of economic, information, engineering and management sciences. These research works demonstrate that advancement of robust decision-support and policyanalysis methods and progression of vigorous information technologies are critically important for addressing intrinsic complexities that exist in many energy and environmental systems, and can effectively facilitate energy-related and environmental studies in terms of the identification of system parameters, the reflection of interactive relationships, the formulation of modeling approaches, the interpretation of modeling outputs, and the generation of desired policies.
Received: 19 June 2012 Accepted: 14 August 2012

Published: 14 August 2012

\section{References}

Huang GH, Chang NB (2003) The perspectives of environmental informatics and systems analysis. Journal of Environmental Informatics 1(1):1-7

Jin HG, Lior N, Zhang XL (2010) Energy and its sustainable development for China: editorial introduction and commentary for the special issue of Energy. Energy 35(11):4246-4256

Matsuhashi R, Hikita K, Ishitani H (1996) Model analyses for sustainable energy supply taking resource and environmental constraints into consideration. Energy Conversion and Management 37(6-8):1253-1258

Olabi AG (2012) Developments in sustainable energy and environmental protection. Energy 39(1):2-5

Schweizer-Ries P (2008) Energy sustainable communities: environmental psychological investigations. Energy Policy 36(11):4126-4135

Verderame PM, Elia JA, Li J, Floudas CA (2010) Planning and scheduling under uncertainty: A Review Across Multiple Sectors. Ind Eng Chem Res 49(9):39934017

Yuksel I (2012) Global warming and environmental benefits of hydroelectric for sustainable energy in Turkey. Renewable and Sustainable Energy Reviews 16 (6):3816-3825

doi:10.1186/2193-2697-1-3

Cite this article as: Cai: Editorial: Informatics for sustainable energy development and environmental management. Environmental Systems Research 2012 1:3.

\section{Submit your manuscript to a SpringerOpen ${ }^{\circ}$ journal and benefit from:}

- Convenient online submission

- Rigorous peer review

- Immediate publication on acceptance

- Open access: articles freely available online

- High visibility within the field

- Retaining the copyright to your article

Submit your next manuscript at springeropen.com 